\title{
Cost Optimization of Mortars Containing Different Pigments and Their Freeze-Thaw Resistance Properties
}

\author{
Sadık Alper Yıldızel, ${ }^{1}$ Gökhan Kaplan, ${ }^{2}$ and Ali Uğur Öztürk ${ }^{1}$ \\ ${ }^{1}$ Faculty of Engineering, Department of Civil Engineering, Celal Bayar University, Manisa, Turkey \\ ${ }^{2}$ Kastamonu Vocational School of Higher Education, Kastamonu University, Kastamonu, Turkey \\ Correspondence should be addressed to Sadık Alper Yıldızel; sadikalper.yildizel@cbu.edu.tr
}

Received 12 October 2015; Accepted 22 December 2015

Academic Editor: Juan J. Del Coz Díaz

Copyright (C) 2016 Sadık Alper Yıldızel et al. This is an open access article distributed under the Creative Commons Attribution License, which permits unrestricted use, distribution, and reproduction in any medium, provided the original work is properly cited.

Nowadays, it is common to use colored concrete or mortar in prefabricated concrete and reinforced concrete construction elements. Within the scope of this study, colored mortars were obtained with the addition of brown, yellow, black, and red pigments into the white cement. Those mixtures are examined for their compressive strength, unit weight, water absorption, and freeze-thaw resistance. Subsequent to comparison of these properties, a cost optimization has been conducted in order to compare pigment costs. The outcomes showed that the pore structure in architectural mortar applications plays an important role in terms of durability. And cost optimization results show that light colored minerals can be used instead of white cements.

\section{Introduction}

Colored concrete is an architectural design element which is produced as a response to the unaesthetic outlook of traditional concrete. White cement and colorants are used in order to obtain colored concrete. However, it offers an aesthetical look, and colored concrete has some physical disadvantages such as efflorescence and low processability [1].

Use of colored concrete in mortar and concrete block, cement-based roofing materials, and precast concrete applications has been increasing recently. Colored concrete applications use pigments for durable color [2]. Hematite (red, orange, and purple), goethite (yellow), lepidocrocite (brown), calcite and dolomite (white), celadonite and malachite (green), quartz (white and translucent), and many others have been used as pigments since the antique ages. On the other hand, litharge (red), massicot (yellow), red lead (orange), and chrome oxide (green) are being used as synthetic pigments $[3,4]$.

Pigments are powdered material with finer grains compared to cement. Pigments used with cement-based composites are sieved using sieve opening number 200. Thus, it is expected for the mixtures water/pigment ratio to be higher for a specific thickness. Nevertheless, pigment's size and surface properties also have an impact on the water/pigment ratio. Pigment's water requirement and dosage are among the important factors predicting its colour durability. Pigments also have an impact on the concrete shrinkage [5, 6]. Properties such as setting time, lightfastness, durability, mechanical properties, heat resistance, and soluble salt content gain importance in colored concrete. The cast system and the release agent used are of importance for a successful colored concrete application along with the aforementioned properties [7-11]. Cohesion of the mortar is increased when pigments are used in the mortar mixture [12] therefore reducing filler material ratio used in the mixture $[13,14]$.

Lee et al. [15], in a study conducted on keyed concrete blocks using iron oxide pigment as colorant, stated that the pigment/cement ratio must be less than $4 \%$.

Bruce and Rowe [5] used inorganic pigments as colorant and found that these pigments are 10 times finer than cement. Thus, they found a decrease in the viscosity and thickness of mortars.

Jang et al. obtained colored mortars using white cement, blast-furnace slag and inorganic pigments. Viscosity of the mortar was decreased with the addition of pigments, yet it was improved with the addition of blast-furnace slag. However, addition of blast-furnace slag also alleviated the 
TABLE 1: The chemical and physical properties of CEM I $52.5 \mathrm{R}$ cement.

\begin{tabular}{lllc}
\hline \multicolumn{2}{c}{ Chemical properties (\%) } & & \multicolumn{1}{c}{ Physical and mechanical properties } \\
\hline $\mathrm{SiO}_{2}$ & 21.6 & Specific weight & 3.06 \\
$\mathrm{Al}_{2} \mathrm{O}_{3}$ & 4.05 & Specific surface $\left(\mathrm{cm}^{2} / \mathrm{gr}\right)$ & 4600 \\
$\mathrm{Fe}_{2} \mathrm{O}_{3}$ & 0.26 & Whiteness $(\%)$ & 85.5 \\
$\mathrm{CaO}$ & 65.7 & Initial setting (min.) & 100 \\
$\mathrm{MgO}$ & 1.30 & Final setting (min.) & 130 \\
$\mathrm{Na}_{2} \mathrm{O}$ & 0.30 & Water used for consistency (\%) & 30 \\
$\mathrm{~K}_{2} \mathrm{O}$ & 0.35 & Volume constancy (mm) & 1.0 \\
$\mathrm{SO}_{3}$ & 3.30 & Remnants obtained using 0.045 sieve $(\%)$ & 1.0 \\
$\mathrm{Free}_{\mathrm{CaO}}$ & 1.60 & Remnants obtained using 0.090 sieve $(\%)$ & 0.1 \\
$\mathrm{Chloride}(\mathrm{Cl})$ & 0.01 & Compressive strength for 2 days $(\mathrm{MPa})$ & 37.0 \\
Insolubles & 0.18 & Compressive strength for 7 days $(\mathrm{MPa})$ & 50.0 \\
Loss on ignition & 3.20 & Compressive strength for 28 days $(\mathrm{MPa})$ & 60.0 \\
\hline
\end{tabular}

TABLE 2: Physical properties of the aggregate used in the mixtures.

\begin{tabular}{|c|c|c|c|c|c|c|c|c|c|}
\hline Sieve aperture size & $1 \mathrm{~mm}$ & $710 \mu \mathrm{m}$ & $500 \mu \mathrm{m}$ & $355 \mu \mathrm{m}$ & $250 \mu \mathrm{m}$ & $180 \mu \mathrm{m}$ & $125 \mu \mathrm{m}$ & $90 \mu \mathrm{m}$ & $63 \mu \mathrm{m}$ \\
\hline Production range (\%) & 0 & 0 & 0 & 0.2 & 0.3 & 20.1 & 60.4 & 16.1 & 1.8 \\
\hline Mean grain size $(\mu \mathrm{m})$ & & & & & $140-170$ & & & & \\
\hline Clay content (\%) & & & & & $0.6-0.8$ & & & & \\
\hline Specific weight & & & & & 2.68 & & & & \\
\hline AFS value $(\%)$ & & & & & 84.6 & & & & \\
\hline
\end{tabular}

efflorescence problem therefore increasing the long-term durability [1].

Colored mortars were obtain under laboratory conditions with the addition of brown, yellow, black, and red pigments into white cement in this study. The cement mortars obtained are examined for their compressive strength, unit weight, water absorption, and freeze-thaw resistance.

\section{Material and Method}

CEM I 52.5 R (White Portland Cement) manufactured by Çimsa cement manufacturing plant which complies with the TS EN 197-1 and ASTM C150 standards was preferred for the cement applications. The chemical and physical properties of CEM I $52.5 \mathrm{R}$ cement are shown in Table 1. Polycarboxylate based third generation water reducer was used as the chemical agent.

Silica sand of AFS 80 to 100 (AFS is obtained by multiplying the sand grammage per sieve and DIN factor for each sieve and then division by the total grammage) was chosen as the aggregate to be used in the mixtures. Properties of the silica sand are given in Table 2.

$\mathrm{Fe}_{2} \mathrm{O}_{3}$ based 4 different pigments were used for the architectural mortar application. Technical specifications of the pigments used are given in Table 3.

Mortars obtained during the experiments were cubic samples of $5 \mathrm{~cm} \times 5 \mathrm{~cm} \times 5 \mathrm{~cm}$ dimensions. Materials used in the preparation of the mixtures are given in Table 4 (for $1 \mathrm{~m}^{3}$ ). Slump value was taken $4 \mathrm{~cm}$ for all the mixtures. For slump test, a cylindrical funnel (height: $60 \mathrm{~mm}$, inner radius: $57 \mathrm{~mm}$, and outer radius: $65 \mathrm{~mm}$ ) is used. The mortar
TABLE 3: Technical specifications of pigments.

\begin{tabular}{lcccc}
\hline Pigment type & Brown & Yellow & Black & Red \\
\hline $\begin{array}{l}\mathrm{SiO}_{2}+\mathrm{Al}_{2} \mathrm{O}_{3} \\
(\mathrm{max} \% 100)\end{array}$ & 4 & 1.2 & 3.2 & 4 \\
\hline $\mathrm{Fe}_{2} \mathrm{O}_{3}$ & 96 & 98.8 & 96.8 & 96 \\
\hline Density $\left(\mathrm{g} / \mathrm{cm}^{3}\right)$ & $0.75-1.05$ & $0.45-0.65$ & $0.75-1.05$ & $0.70-1.10$ \\
\hline $\mathrm{pH}$ & $5-8$ & $3.2-7.5$ & $4-8$ & $4-7$ \\
\hline
\end{tabular}

TABLE 4: Material content of $1 \mathrm{~m}^{3}$ mortar mixture.

\begin{tabular}{lccccc}
\hline & Brown & Yellow & Black & Red & Reference \\
\hline Pigment $(\mathrm{g})$ & 1250 & 1250 & 1250 & 1250 & - \\
\hline $\begin{array}{l}\text { Additional water per } \\
\text { 1 g of pigment }(\mathrm{g})\end{array}$ & 4.5 & 13 & 4.13 & 4.75 & - \\
\hline Additional water $(\mathrm{kg})$ & 5.625 & 16.25 & 5.163 & 5.938 & - \\
\hline Aggregate $(\mathrm{kg})$ & 625 & 625 & 625 & 625 & 625 \\
\hline Cement $(\mathrm{kg})$ & 625 & 625 & 625 & 625 & 625 \\
\hline Superplasticizer $(\mathrm{kg})$ & 3.69 & 3.69 & 3.69 & 3.69 & 3.30 \\
\hline Water $(\mathrm{kg})$ & 190 & 190 & 190 & 190 & 190 \\
\hline Slump value $(\mathrm{cm})$ & 4 & 4 & 4 & 4 & 4 \\
\hline
\end{tabular}

samples were tested for their water absorption, unit weight, and compressive strength for 1 day, 7 days, and 28 days. Nevertheless, a freeze-thaw test of 100 cycles was conducted on the mortar samples. Apart from other material mechanical test results and coefficients, F-T resistance factor has a great importance on colored aggregated concrete for preserving 
TABLE 5: Mortar mixture properties.

\begin{tabular}{lccccc}
\hline & Reference & Brown & Yellow & Black & Red \\
\hline Pigment $(\mathrm{g})$ & - & 1.25 & 1.25 & 1.25 & 1.25 \\
\hline $\begin{array}{l}\text { Additional water per } \\
\text { 1 g of pigment }(\mathrm{g})\end{array}$ & - & 4.5 & 13 & 4.13 & 4.75 \\
\hline Additional water $(\mathrm{kg})$ & - & 5.625 & 16.250 & 5.163 & 5.938 \\
\hline Aggregate $(\mathrm{kg})$ & 625 & 625 & 625 & 625 & 625 \\
\hline Cement $(\mathrm{kg})$ & 625 & 625 & 625 & 625 & 625 \\
\hline Superplasticizer $(\mathrm{kg})$ & 3.3 & 3.69 & 3.69 & 3.69 & 3.69 \\
\hline Water $(\mathrm{kg})$ & 190 & 190 & 190 & 190 & 190 \\
\hline Slump value $(\mathrm{cm})$ & 4 & 4 & 4 & 4 & 4 \\
\hline Pigment price $€ / \mathrm{kg}$ & - & 2.58 & 4.32 & 2.28 & 2.58 \\
\hline Cost & $€ \mathbf{1 2 6 . 7}$ & $€ \mathbf{1 3 1 . 3}$ & $€ \mathbf{1 3 4 . 1}$ & $€ \mathbf{1 3 0 . 8}$ & $€ \mathbf{1 3 1 . 3}$ \\
\hline
\end{tabular}

its initial conditions such as freezing and overheating. This type of test puts the concrete specimen through a series of extreme and rapid temperature changes it may face during the transportation and utilization processes. Following every 30 cycles, specimen dimensions and weights are checked and compared with the specimens which are not tested under dynamic temperature changes. Dynamic stability factor was calculated (ASTM C 666: DSF $=P N / M ; P$ : dynamic elasticity factor after $n$ cycles; $N$ : cycle number allowable for decreasing $P ; M$ : total cycle number) and the results are obtained under the acceptable limits. Compression tests were also performed on the samples before and after the freeze-thaw cycle.

Aggregate, pigment, and cement were dry mixed in the coloured mortar production process with pigment addition. Dry mix procedure took approximately 30 seconds. The mixture was then stirred for 2.5 minutes following the addition of water.

\section{Cost Analysis and Optimization}

Cost optimization of the pigments becomes very important depending on its high costs comparing the other ingredients of the mortar. Full factorial experimental design (Minitab ver. 17 demo) was chosen due to the few test quantities. This design method is a good choice when the resources are limited. This experiment also allows the user to examine the effect of each factor on the response data. This study does not comprise the cross-sectional optimization of the final products. Further development and implementation of this approach can be taken into account for further researchers. Mixture features of the mortar using concrete pigments are shown in Table 5.

An optimization survey was conducted in order to identify the optimal pigment to be used in colored concrete production. For this purpose, 12 different functions were used and their properties are given in Table 1 . These functions are maximized for strength and durability properties. Unit weight was maximized taking maximum compactness criteria into consideration. Factors such as water absorption, loss of strength, and cost were minimized.
TABLE 6: Functions used in optimization and their properties.

\begin{tabular}{llc}
\hline Number & Objective function & Property \\
\hline$X_{1}(\mathrm{MPa})$ & Compressive strength for 1 day & Maximum \\
$X_{2}(\mathrm{MPa})$ & Compressive strength for 7 days & Maximum \\
$X_{3}(\mathrm{MPa})$ & Compressive strength for 28 days & Maximum \\
$X_{4}\left(\mathrm{~kg} / \mathrm{m}^{3}\right)$ & Unit weight & Maximum \\
$X_{5}(\%)$ & Water absorption & Minimum \\
$Y_{1}(\mathrm{MPa})$ & 1 day, 100 F-T & Maximum \\
$Y_{2}(\mathrm{MPa})$ & 7 days, 100 F-T & Maximum \\
$Y_{3}(\mathrm{MPa})$ & 28 days, 100 F-T & Maximum \\
$Z_{1}(\%)$ & 1 F-T loss of strength & Minimum \\
$Z_{2}(\%)$ & 7 F-T loss of strength & Minimum \\
$Z_{3}(\%)$ & 28 F-T loss of strength & Minimum \\
$T_{1}(€)$ & Cost & Minimum \\
\hline
\end{tabular}

Four different models were created for 12 different functions as part of the optimization process. These models are summarized in Table 2 . The first model involves the optimization of the concretes only by their physical properties $(X)$. The second model involves the optimization of concretes by their physical properties $(X)$ along with their F-T resistance $(Y)$. The third model involves the optimization of concretes taking the loss of strength $(Z)$ into consideration following the freeze-thaw cycles. The fourth model, on the other hand, defines the optimal mix according to the cost factor $(T)$. The summary of the models can be shown in Table 7.

First Model. The first model involves the optimization of the concrete samples only by their physical properties. Optimization results showed that the optimal mix is the one prepared using black pigment. Table 3 compares the black pigment mix and reference mix. The results obtained from the first model are represented in Table 8 .

Second Model. The second model involves the optimization of concretes samples by their physical along with their durability properties. Black pigment was found to be the optimal mix according to the second model. Table 4 compares the black pigment mix and reference mix. The results achieved from the second model can be obtained from Table 9 .

Third Model. The third model involves the optimization of concretes samples by their physical properties along with their durability properties and their loss of strength. Yellow pigment was found to be the optimal mix according to the third model. Table 5 compares the yellow pigment mix and reference mix. The results obtained from the third model are represented in Table 10.

Fourth Model. The fourth model involves optimization of the concrete samples by all the functions included in the other models and also the cost function. With the inclusion of the cost function, reference mix was found to be the optimal mix. Table 6 shows the function properties of the reference sample. The results obtained from the fourth model are represented in Table 11. 
TABLE 7: Summaries of the models used in optimization.

\begin{tabular}{ll}
\hline Model \# & Model summary \\
\hline 1 & Physical properties $(X)$ \\
\hline 2 & Physical properties-durability $(X+Y)$ \\
\hline 3 & $\begin{array}{l}\text { Physical properties-durability-loss of strength } \\
(X+Y+Z)\end{array}$ \\
\hline 4 & $\begin{array}{l}\text { Physical properties-durability-loss of strength-cost } \\
(X+Y+Z+T)\end{array}$ \\
\hline
\end{tabular}

TABLE 8: Results obtained from the first model.

\begin{tabular}{lccccc}
\hline Function & $X_{1}$ & $X_{2}$ & $X_{3}$ & $X_{4}$ & $X_{5}$ \\
\hline Reference & 14.31 & 32.28 & 46.21 & 2095 & 9.50 \\
\hline Black & 15.78 & 33.14 & 47.35 & 2137 & 8.95 \\
\hline Difference & $10.27 \%$ & $2.66 \%$ & $2.50 \%$ & $2.00 \%$ & $-5.79 \%$ \\
\hline
\end{tabular}

\section{Results and Discussion}

Compressive strength tests were conducted on the 1st, 7 th, and 28th days for the mortars with and without pigment additive and the results obtained are shown in Figure 1.

Mortars obtained using brown, yellow, and black pigments delivered very high performance when compared to the reference sample in the tests conducted on the 1st, 7 th, and 28th days. However, red pigment use has led to a decrease in compressive strength for the tests conducted on the 1st, 7 th, and 28th days. When the compressive strength values for the 28th day were examined, it was found that the addition of black pigment has increased the compressive strength by $2.5 \%$ when compared to the reference mortar.

Coloured mortars were then subjected to $100 \mathrm{~F}-\mathrm{T}$ cycles after being cured for 1 day, 7 days, and 28 days. Compressive strength values obtained after these tests are shown in Figure 2.

Mortar samples which were subjected to the F-T effect after one day of curing have shown $14.4 \%$ loss of strength for the reference sample, while this value was in a range between 16 and $20 \%$ for the samples with pigment additive. Loss of strength decreased for the samples which were cured for 7 days as the hydration process is continued. The reference sample has shown $6.4 \%$ loss of strength after the freeze-thaw cycles conducted on the 28th day. This percentage was $8 \%$ for the brown mortars, 7.2\% for the yellow mortars, and 7.1\% for the black mortars. Freeze-thaw results obtained from the mortar samples with red pigment additive, on the other hand, were on the contrary. Red mortars were negatively affected by the F-T process on the 1st and 7th days, yet this effect was not observable on the 28th day.

The impact of pigment type on the water absorption and unit weight is shown in Figure 3. As we can see in Figure 3, results obtained from the mortar produced using brown pigment were the closest to the reference sample. Water absorption ratio increases with the increasing pore ratio of the mortar samples. This predicts the high water absorption level and low unit weight obtained from the red mortar. However, both water absorption level and unit weight of yellow mortar were higher than the brown mortar.

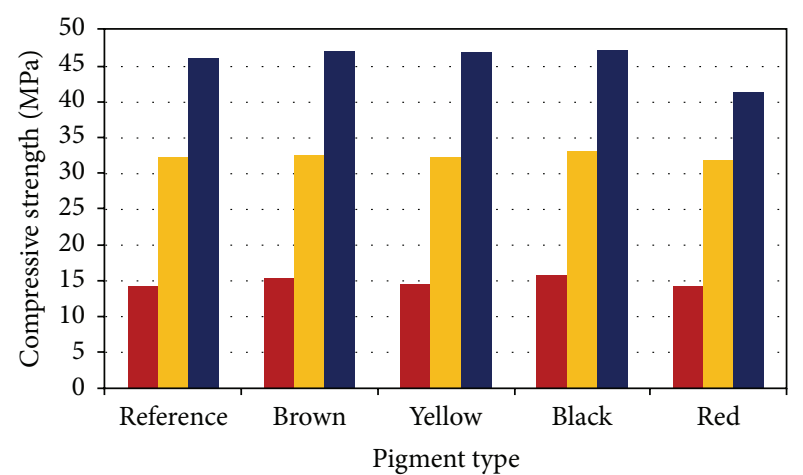

1 day
7 day
28 day

FIGURE 1: Compressive strength tests for mortars obtained using different pigments.

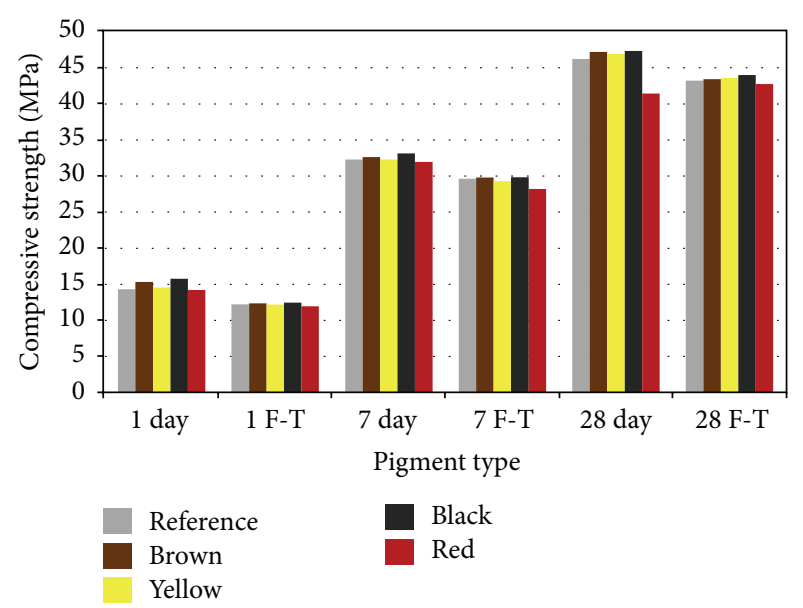

FIGURE 2: Results of the F-T tests conducted on the mortar samples.

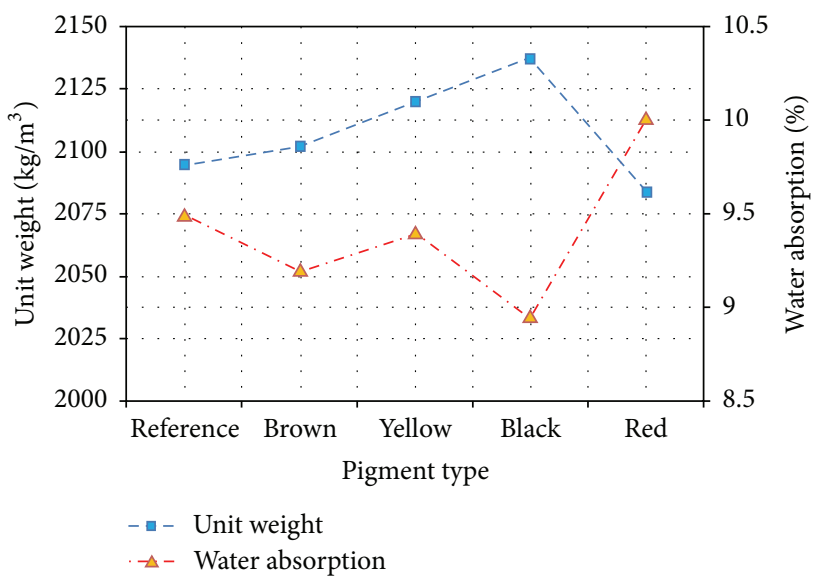

FIGURE 3: The impact of pigment type on the water absorption and unit weight. 
TABLE 9: Results obtained from the second model.

\begin{tabular}{lcccccccc}
\hline Function & $X_{1}$ & $X_{2}$ & $X_{3}$ & $X_{4}$ & $X_{5}$ & $Y_{1}$ & $Y_{2}$ \\
\hline Reference & 14.31 & 32.28 & 46.21 & 2095 & 9.50 & 12.24 & 29.63 & 43.24 \\
\hline Black & 15.78 & 33.14 & 47.35 & 2137 & 8.95 & 12.48 & 29.84 \\
\hline Difference & $10.27 \%$ & $2.66 \%$ & $2.50 \%$ & $2.00 \%$ & $-5.79 \%$ & $1.96 \%$ & $0.71 \%$ & $1.78 \%$ \\
\hline
\end{tabular}

TABLE 10: Results obtained from the third model.

\begin{tabular}{lcccccccccccc}
\hline Function & $X_{1}$ & $X_{2}$ & $X_{3}$ & $X_{4}$ & $X_{5}$ & $Y_{1}$ & $Y_{2}$ & $Y_{3}$ & $Z_{1}$ & $Z_{2}$ & $Z_{3}$ \\
\hline Reference & 14.31 & 32.28 & 46.21 & 2095 & 9.50 & 12.24 & 29.63 & 43.24 & 14.47 & 8.21 & 6.43 \\
\hline Yellow & 14.54 & 32.29 & 46.95 & 2120 & 9.40 & 12.20 & 29.31 & 43.58 & 16.09 & 9.23 & 7.18 \\
\hline Difference & $1.60 \%$ & $0.03 \%$ & $1.60 \%$ & $1.19 \%$ & $-1.05 \%$ & $-0.33 \%$ & $-1.08 \%$ & $0.79 \%$ & $-1.62 \%$ & $-1.02 \%$ & $-0.75 \%$ \\
\hline
\end{tabular}

TABLE 11: Properties of the reference mix.

\begin{tabular}{lc}
\hline$X_{1}$ & 14.31 \\
$X_{2}$ & 32.28 \\
$X_{3}$ & 46.21 \\
$X_{4}$ & 2095 \\
$X_{5}$ & 9.5 \\
$Y_{1}$ & 12.24 \\
$Y_{2}$ & 29.63 \\
$Y_{3}$ & 43.24 \\
$Z_{1}$ & 14.47 \\
$Z_{2}$ & 8.21 \\
$Z_{3}$ & 6.43 \\
$T_{1}$ & 126.7 \\
\hline
\end{tabular}

The impact of pigment type on the F-T process (obtained from samples cured for 28 days) is shown in Figure 4.

As we can see in Figure 4, black mortar with the lowest water absorption level was the one which delivered the highest compressive strength after 100 F-T cycles. Red mortars gave the lowest compressive strength values before F-T process, yet an increase in the strength was observable after the cycles. Pore structure increases with the increasing water absorption levels while compressive strength decreases.

It was found that the impact of F-T cycles was diminished with the decreasing water absorption capacity and increasing unit weight. The findings of this study are in line with the previous experimental studies available in the literature.

Previous research suggests that strength and durability properties are negatively affected by the increasing pore structure of the mortar. The experimental study showed that the pore structure in architectural mortar applications plays an important role in terms of durability.

\section{Conclusion}

This study investigated the F-T resistance of architectural mortars obtained using pigments with different properties. The results obtained from this experimental study are detailed below.

It was found that brown, yellow, and black pigments contributed to the compressive strength, yet the red pigment

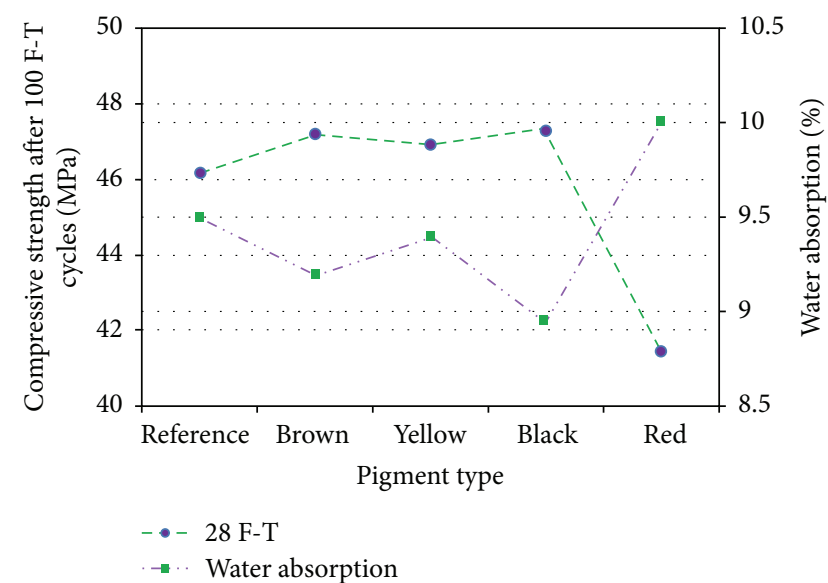

FIGURE 4: The impact of pigment type on the F-T process (samples cured for 28 days).

had an adverse effect on the compressive strength resulting in loss of resistance. Strength and durability tests showed that the black mortar has superior properties when compared to the reference sample.

Low water absorption level and high unit weight which are the characteristics of black mortar suggest that black mortar has a limited pore structure. In the light of these findings, it is clear that the use of black pigments in architectural mortar production will improve its strength and durability properties to a point superior to the mortars produced using other pigments.

The strength values of mortars produced using red pigments obtained from the 1st, 7 th, and 28th days were lower than the other mortars. It was found that the addition of red pigment increases the pore ratio in the mortar according to the unit weight and water absorption analyses. The increase in the pore ratio negatively affects the strength and durability properties of the mortar.

Additional measure might be taken in order to increase the mortar strength when red pigment is used (i.e., reducing water/cement ratio). Air entrainer admixture must be preferred for freeze-thaw resistance.

It was found that the use of pigments in architectural mortar applications (except for red pigment) contributes to the strength of the mortar, therefore having an impact on the 
freeze-thaw resistance of the material. When the strength loss is assessed, it would be fair to say that coloured mortars with similar properties to the reference mortar are resistant to the freeze-thaw effect.

It would be possible to obtain stronger, coloured architectural building elements with additional measures (i.e., air entrainer use) when severe freeze-thaw effect is in question. The impact of water absorption and unit weight on freezethaw process was found to be similar with the available literature results and proved the importance of the pore structure.

The use of yellow and black pigments has a positive effect on the strength and durability properties of concrete. Pore ratio was decreased leading to reduced water absorption values when black and yellow pigments were used. Overall, the use of any pigment has a positive effect on the strength and durability properties of concrete. Optimization results showed that the optimal pigments are black and yellow pigments. However, it was found that colored concrete cannot match the economic advantages traditional concrete offers when cost factor is brought into the equation. One of the most significant drawbacks of colored concrete is the unit price of pigment. Therefore, the use of pigments increases the unit cost of concrete having a direct impact on construction costs. Thus, the unit costs may be reduced to a point with the optimization of other material ratios. Particularly, lowcost materials such as light-colored mineral admixtures can be used instead of costly white cement.

\section{Conflict of Interests}

The authors certify that they have no affiliations with or involvement in any organization or entity with any financial interest (such as honoraria; educational grants; participation in speakers' bureaus; membership, employment, consultancies, stock ownership, or other equity interests; and expert testimony or patent-licensing arrangements) or nonfinancial interest (such as personal or professional relationships, affiliations, knowledge, or beliefs) in the subject matter or materials discussed in this paper.

\section{References}

[1] H.-S. Jang, H.-S. Kang, and S.-Y. So, "Color expression characteristics and physical properties of colored mortar using ground granulated blast furnace slag and White Portland Cement," KSCE Journal of Civil Engineering, vol. 18, no. 4, pp. 1125-1132, 2014.

[2] T. C. Patton, Pigment Handbook, Wiley, New York, NY, USA, 1973.

[3] M. C. Z. Ares, E. V. González, A. I. T. Gómez, and J. M. Fernández, "An easy method to estimate the concentration of mineral pigments in colored mortars," Dyes and Pigments, vol. 101, pp. 329-337, 2014.

[4] J. M. Fernández Rodríguez and J. A. Fernández Fernández, "Application of the second derivative of the Kubelka-Munk function to the semiquantitative analysis of Roman paintings," Color Research and Application, vol. 30, no. 6, pp. 448-456, 2005.
[5] S. M. Bruce and G. H. Rowe, "The influence of pigments on mix designs for block paving units," in Proceedings of the 4th International Conference on Concrete Block Paving, vol. 2, pp. 117-124, Auckland, New Zealand, 1992.

[6] H.-S. Lee, J.-Y. Lee, and M.-Y. Yu, "Influence of iron oxide pigments on the properties of concrete interlocking blocks," Cement and Concrete Research, vol. 33, no. 11, pp. 1889-1896, 2003.

[7] M. Karagüler, "Mimarlıkta beton, mimari beton," THBB ReadyMix Concrete Periodical, no. 53, p. 56, 2002.

[8] M. Karagüler, "Mimari Beton ve Kalıp," ТНBB Ready-Mix Concrete Periodical, no. 57, p. 68, 2003.

[9] E. Püttbach, "New pigments for the colouring of construction materials processing advantages at zero tariff," Magazine of Concrete Precasting Plant and Technology, no. 8, pp. 104-107, 1997.

[10] U. Hahn, "Coloured concrete-nature has the aggregates," Magazine of Concrete Precasting Plant and Technology, vol. BFT 1, pp. 78-88, 1998.

[11] E. V. D. Busken, "Innovations in concrete block paving in Belgium," in Proceedings of the 1st International Symposium for Street Furniture, Istanbul, Turkey, 2001.

[12] A. López, J. M. Tobes, G. Giaccio, and R. Zerbino, "Advantages of mortar-based design for coloured self-compacting concrete," Cement and Concrete Composites, vol. 31, no. 10, pp. 754-761, 2009.

[13] M. Collepardi and A. Passuelo, "The best SCC: stable, durable and colourable," in Proceedings of the 4th International ACI/CANMET Conference on Quality of Concrete Structures and Recent Advances in Concrete Materials and Testing-Furnas Centrais Eletricas SA, P. Helene, T. C. Holland, E. Pazzini, and R. Bittecourt, Eds., Civil Engineering Technological Center, Goibnia, Brasil, 2005.

[14] V. Corinaldesi, S. Monosi, and M. L. Ruello, "Influence of inorganic pigments' addition on the performance of coloured SCC," Construction and Building Materials, vol. 30, pp. 289-293, 2012.

[15] H.-S. Lee, J.-Y. Lee, and M.-Y. Yu, "Influence of inorganic pigments on the fluidity of cement mortars," Cement and Concrete Research, vol. 35, no. 4, pp. 703-710, 2005. 

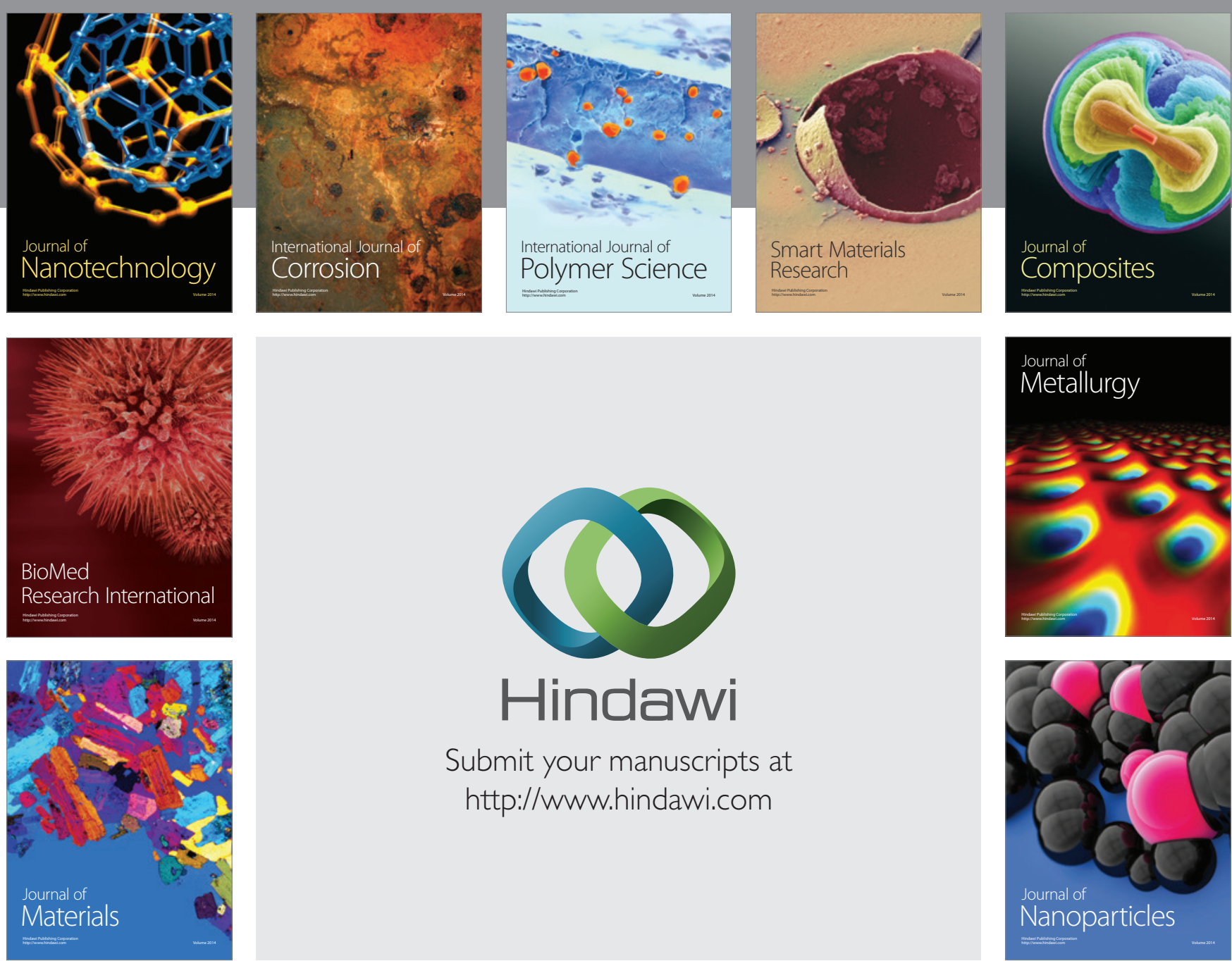

\section{Hindawi}

Submit your manuscripts at

http://www.hindawi.com

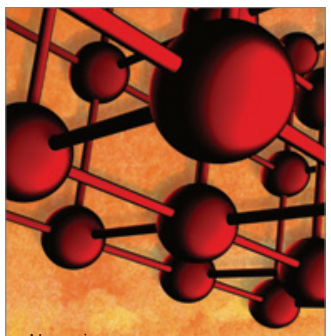

Materials Science and Engineering
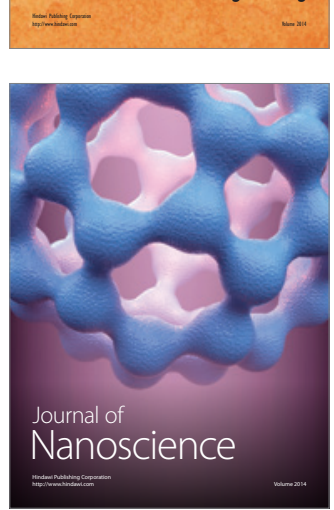
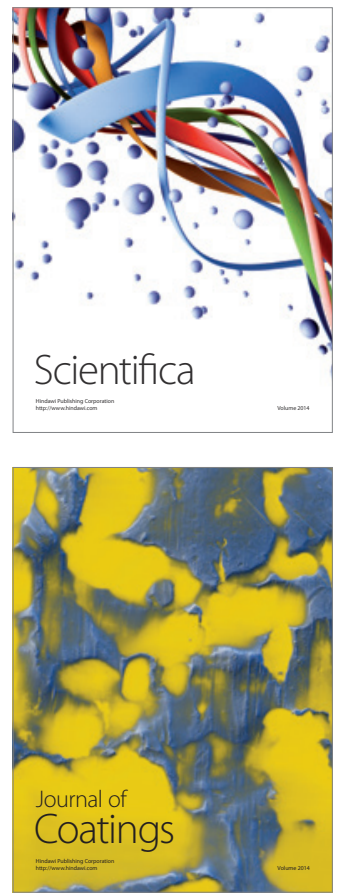
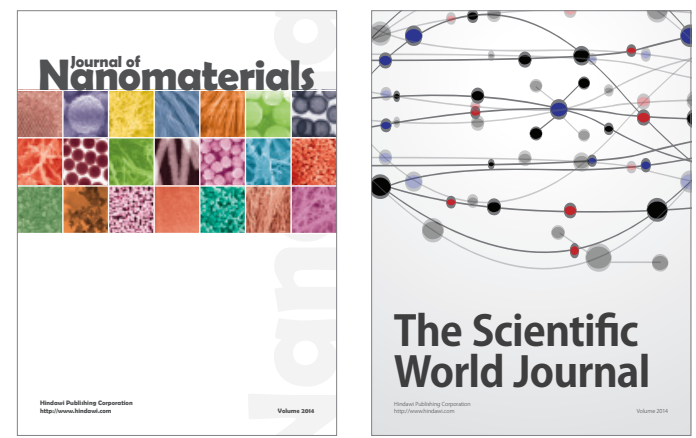

The Scientific World Journal
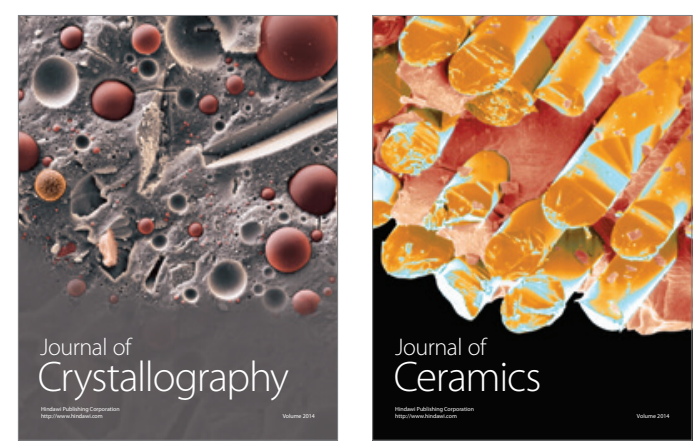
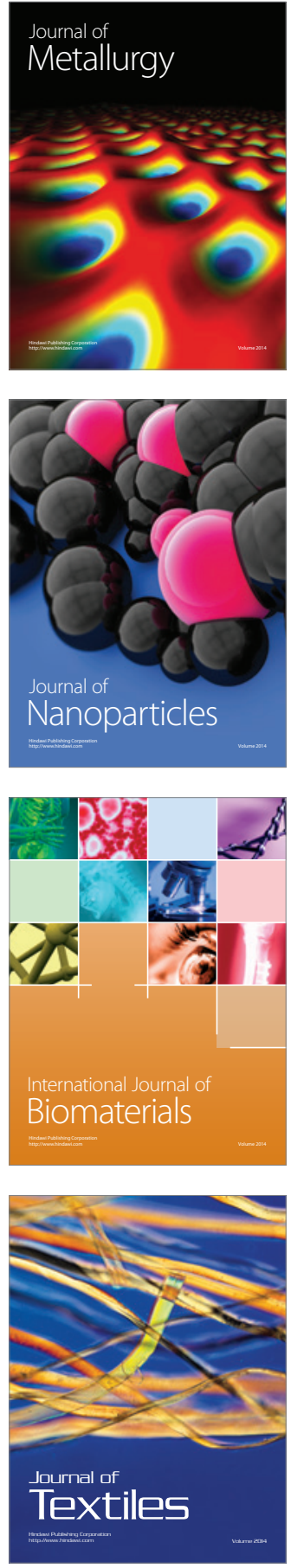